\title{
Effects of queen mating status, pre-diapause weight and pupae's sex on colony initiation in small-scale rearing of Bombus terrestris
}

\author{
Gherardo Bogo ${ }^{1,2}$, Natasha de MANINCOR ${ }^{2,3}$, Alessandro Fisogni ${ }^{2,3}$, Marta Galloni ${ }^{2}$, \\ Laura BORTOLOTTI ${ }^{1}$ \\ ${ }^{1}$ Consiglio per la ricerca in agricoltura e l'analisi dell'economia agraria, Centro di Ricerca Agricoltura e Ambiente \\ (CREA-AA), Via di Saliceto 80, 40128, Bologna, Italy \\ ${ }^{2}$ Dipartimento di Scienze Biologiche, Geologiche e Ambientali, Università di Bologna, Via Irnerio 42, 40126, Bologna, \\ Italy \\ ${ }^{3}$ UMR 8198 - Evo-Eco-Paleo, Université de Lille, CNRS, 59000, Lille, France
}

Received 8 November 2016 - Revised 15 June 2017 - Accepted 30 June 2017

\begin{abstract}
Diapause control and colony initiation are among the major problems encountered in the rearing of bumble bee colonies in small-scale rearing. In this study, we used Bombus terrestris queens obtained from commercial colonies to investigate (1) the diapause survival in virgin and mated queens, (2) the diapause and colony initiation performance of mated bumble bee queens in relation to the pre-diapause weight and (3) the effect of pupae's sex on colony initiation. We found that diapause survival is negatively affected by mating and by the low pre-diapause weight, but first egg deposition and development of the first adult worker were delayed in heavy queens. We found no significant differences in the egg-laying success in relation to pupae's sex; however, queens stimulated with queen pupae laid more eggs per cell and developed a first brood larger than those stimulated with male pupae. Our results can be useful in small-scale rearing, including the rearing of wild queens for conservation purposes.
\end{abstract}

bumble bee / colony initiation / egg laying / experimental rearing / diapause

\section{INTRODUCTION}

Bumble bees are annual eusocial insects, whose colonies develop from spring to late summer. The colony is comprised of a single queen and numerous workers (between 50 and 400 depending on the species) (Kwong et al. 2014); in the late phase of colony development, new queens and males are produced, which subsequently leave the colony for mating. In nature, mated queens survive winter in a state of diapause, inside small cavities (hibernacula), often situated in

Corresponding author: G. Bogo,

gherardo.bogo2@unibo.it

Manuscript Editor: James Nieh north-facing banks or slopes. Diapause lasts 69 months depending on spring temperature (Alford 1969). To survive this long period, queens need large fat reserves that are built up prior to diapause (Beekman et al. 2000). Diapause ends in early spring and queens leave the hibernacula to found new colonies.

Bumble bees are very important pollinators of wild plants as well as crops. Since 1988, bumble bees are reared on a mass scale to pollinate glasshouse crops (Beekman et al. 2000; Velthuis and Van Doorn 2006). While commercial bumble bee growers appear to be able to successfully mate and hibernate queens and initiate colonies, the exact conditions which result in the best outcomes remain unclear because the information is not publicly available. Hence, the need remains to study 
the conditions under which the rearing of bumble bees is optimal (Pouvreau and Marilleau 1977; Röseler 1985; Ptácek 2001).

Bumble bee rearing can be started from queens collected in the wild or queens obtained from commercial colonies. Starting from wild queens can be difficult because it risks the introduction of parasites and diseases (Shykoff and SchmidHempel 1991; van Der Steen 2008). In fact, wild queens, who are not selected to artificial settings, often fail to survive diapause and register a low laying success (Bortolotti et al. 2016). Starting from queens obtained from commercial colonies is a way to overcome these inconveniences, but even so, diapause and colony initiation represent the most critical steps.

Previous studies on Bombus terrestris demonstrated the importance of diapause duration (Beekman et al. 1998; Gösterit and Gürel 2009), diapause temperature (Velthuis 2002; Amin et al. 2007) and queen weight (Beekman et al. 1998) on queen survival rate. Beekman et al. (1998) indicated $0.6 \mathrm{~g}$ as the lowest weight limit at which queens can survive the diapause and $0.8 \mathrm{~g}$ as the mean weight of pre-diapausing queens, while higher weights did not influence queen survival. Nevertheless, queen diapause survival shows a great variability among different rearing studies (Gürel and Gösterit 2008; Yoon et al. 2008).

Another critical phase in artificial bumble bee rearing is colony initiation. Several techniques have been described to initiate colony rearing in captivity and all include egg-laying stimulation, such as placing two queens together or adding 1-5 newly emerged bumble bee or honey bee workers to the laying queen (Sladen 1912; Duchateau 1991; Ptacek 1991; Van Den Eijnde et al. 1991; Gretenkord and Drescher 1997) or using a cocoon containing a live male pupa (Duchateau 2000; Yeninar et al. 2000; Kwon et al. 2003; Gürel and Gösterit 2008).

Queens also vary considerably in their egglaying success, depending on which stimulation method is used, and may vary between about 55 and $90 \%$ both in wild queens (Pridal and Hofbauer 1998; Bortolotti et al. 2016) and in commercial queens (Beekman et al. 1998; Kwon et al. 2003). Mated and virgin queens are both able to survive diapause (Greeff and Schmid-Hempel
2008) and they cannot be distinguished from each other. Consequently, virgin queens can be wrongly used to start a new colony, reducing egg-laying success.

The aim of this study was to determine the effects of queen mating status, pre-diapause weight and pupae's sex on the rearing success of $B$. terrestris starting from commercial colonies.

\section{MATERIALS AND METHODS}

This study was carried out over 3 consecutive years (2013-2015) using a total of 897 bumble bee queens, 731 of which were mated and 166 were virgins. Queens were collected from 14 different colonies (4 colonies in 2013, 4 in 2014 and 6 in 2015).

\subsection{Queen mating and diapause}

Queens and males of B. terrestris (subspecies terrestris ) were obtained from commercial colonies (Bioplanet S.c.a., Cesena, Italy), maintained in laboratory at $25 \pm 1{ }^{\circ} \mathrm{C}$ and $60 \pm 10 \% \mathrm{RH}$, in continuous darkness, and fed with fresh frozen pollen. Queens were let free to mate in meshsided flight cages $(40 \times 40 \times 75 \mathrm{~cm})$ under natural light. We used 2-10-day-old virgin queens and 620 -day-old virgin males to use only receptive and fertile individuals, following Tasei et al. (1998) and Coppée et al. (2011). Males and queens were collected from different colonies respectively to avoid sibling matings. Mating pairs were removed from the mating cage during copulation and put in other flight cages. After mating, males were discarded and only mated queens were kept together inside the cages (up to 50) for a week, fed with fresh frozen multifloral pollen and $50 \%$ sucrose solution, at laboratory temperature (about $20^{\circ} \mathrm{C}$ ) and natural dark/light cycle. The 166 virgin queens were put for the same period in the flying cages without males and treated in the same way as mated queens. After a week, all the survived queens were individually weighed and divided into three categories depending on their weight $(<0.6 \mathrm{~g}$, "light queens", $N=40$; 0.6-0.8 g, "medium queens", $N=307 ;>0.8 \mathrm{~g}$, "heavy queens", $N=384)$. The choice of these ranges was derived from the results of Beekman et al. (1998). 
Artificial diapause was induced by moving queens in a not-ventilated plastic box, filled with commercial non-treated topsoil, in a fridge at $15{ }^{\circ} \mathrm{C}$ for a week (as transition period) and then 3 months at $5{ }^{\circ} \mathrm{C}$. After this period, diapause survival was checked.

\subsection{Post-diapause and colony initiation}

Diapause was interrupted by removing queens from the fridge and placing them (up to 50) in wooden flight cages $(40 \times 40 \times 75 \mathrm{~cm})$ at ambient temperature and natural dark/light cycle, equipped with fresh frozen pollen and sucrose syrup ad libitum to allow the recovery of energy reserves and stimulate ovary maturation. Survival was checked after 7 days and reported as "post-diapause survival".

Mated queens were then placed individually into small plastic boxes $(15 \times 9 \times 5 \mathrm{~cm})$ to start deposition ("starting boxes") and moved in a climate room $\left(29 \pm 1{ }^{\circ} \mathrm{C}\right.$ and $60 \pm 10 \% \mathrm{RH}$, continuous darkness), while virgin queens were discarded. Each box was perforated along the sides to allow ventilation and equipped with a piece of blotting paper at the bottom, a feeder with fresh frozen pollen (changed three times a week to avoid fermentation and mould) and a syringe filled with syrup, which was renewed once a week. Boxes were kept constantly clean and blotting paper was changed when necessary.

\subsection{Egg-laying stimulation}

In order to stimulate egg laying, one young pupa collected from commercial colonies was added to each box and replaced with a new one once a week in case of no deposition (Kwon et al. 2003; Gürel and Gösterit 2008). Young pupae are more efficient in stimulating queen egg laying and they can be discriminated by older ones based on the colour: 1-2-day-old cocoons are whitish and soft, while older cocoons become increasingly greyish with ageing (Kwon et al. 2003). Pupae were fixed vertically or inclined of $45^{\circ}$ at most with honeybee wax on a plastic Petri dish $(6 \mathrm{~cm}$ diameter). When adults emerged from the pupae, they were removed. After 4 weeks, queens that did not lay eggs were discarded.
Among queens placed in the starting boxes, 363 were divided into two groups: the first group $(N=187)$ was stimulated with a queen pupa; the second $(N=176)$ with a male one. Pupae were randomly assigned ensuring that each queens' size category had both pupae types approximately in equal number.

\subsection{Colony development}

When the first adult worker emerged, each colony was transferred to a larger plastic box $(25 \times 15 \times 14 \mathrm{~cm})$. Data on colony development were then recorded by monitoring each colony three times a week. We registered the following data: the time elapsed from the placing of the queen in the starting box to the first egg cell deposition (bumble bee eggs are laid inside wax cells); the number of egg cells produced in the first brood (the whole colony progeny can be divided into three broods, easily distinguishable; see Duchateau and Velthuis 1988); the number of discarded larvae (number of dead larvae found in the starting box); the number of developed larvae and pupae in the first brood; the timing of emergence of the first worker and the starting of second brood deposition (both calculated from the deposition of the first egg); the life span of queens (calculated from queen placing in the starting box until death).

To avoid disturbance, we did not count the exact number of eggs laid in each brood cell; therefore, the mean number of eggs per cell in the first brood was estimated as in

$$
\frac{\mathrm{n}^{\circ} \text { of pupae }+\mathrm{n}^{\circ} \text { of discarded larvae }}{\mathrm{n}^{\circ} \text { of egg cells }}
$$

\subsection{Statistical analysis}

Differences among qualitative data (diapause and post-diapause survival, egg laying, second brood deposition and first worker emerged) were analysed by Pearson's chi-square tests with Yates' correction. Quantitative data on colony performance were firstly tested for normality (Kolmogorov-Smirnov and Shapiro-Wilk tests) and then square root transformed to achieve normality. 

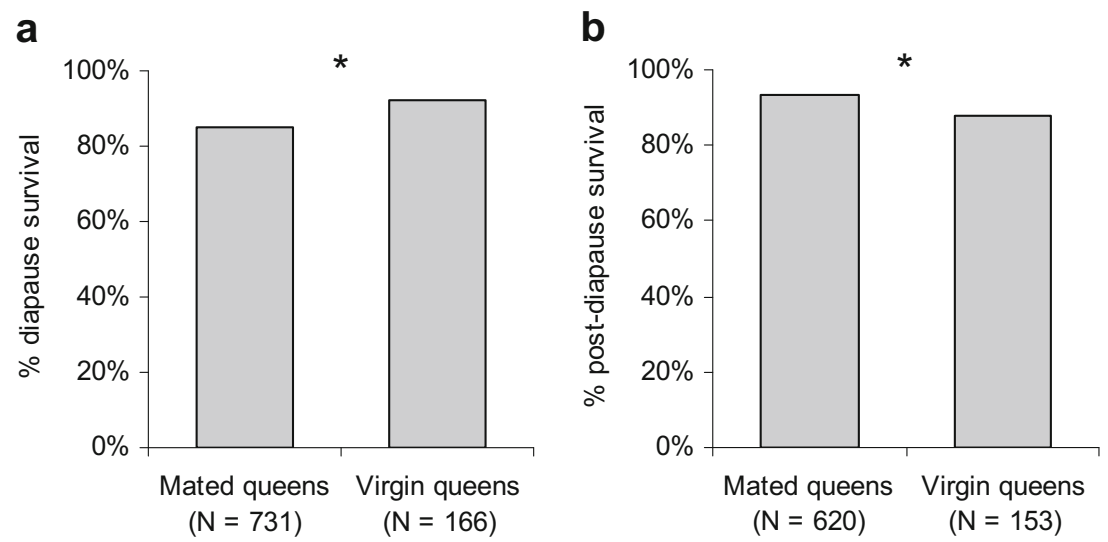

Figure 1. Percentage of mated and virgin queens that survived to $\mathbf{a}$ diapause period and $\mathbf{b}$ post-diapause period. * $P$ values below 0.05 with Pearson's chi-square test with Yates' correction.

Subsequently, they were analysed by independent-samples $t$ test. Statistical analysis was performed with STATISTICA software (StatSoft Italia srl 2005).

\section{RESULTS}

\subsection{Effects of mating status on queen survival}

The analysis of queen survival depending on the mating status showed that virgin queens were significantly more likely to survive diapause period, but less during the post-diapause period than mated queens $\left(\chi_{1}^{2}=5.54\right.$, $P=0.019$ and $\chi^{2}{ }_{1}=4.63, P=0.031$, respectively) (Figure 1).

\subsection{Effect of queen weight on diapause survival and colony initiation}

Given the low number of light queens $(N=40)$, they were excluded from the statistical analyses and only discussed qualitatively. Heavy queens had higher success in diapause survival but a lower number of their colonies achieved the emergence of the first workers, compared to those initiated by medium queens (Table I).

Results of colony development performance of mated queens belonging to the two weight groups showed that heavy queens required more days to reach first egg deposition, and first adult emergence occurred later than medium queens (Table II).

Considering all queens from the three weight categories (Figure 2), it seems that light queens

Table I. Percentage of queens of medium and heavy weight before entering diapause that survived to diapause and post-diapause period and their success with respect to time until egg laying, production of second brood and emergence of the first worker

\begin{tabular}{lcccc}
\hline Queen/colony performances & Medium queens & Heavy queens & $\chi^{2}$ & $P$ \\
\hline Diapause survival & $83.06 \%(N=307)$ & $90.63 \%(N=384)$ & 8.11 & 0.004 \\
Post-diapause survival & $92.55 \%(N=255)$ & $93.39 \%(N=348)$ & 0.06 & 0.811 \\
Egg laying & $62.80 \%(N=207)$ & $59.18 \%(N=267)$ & 0.50 & 0.480 \\
Second brood deposition & $80.00 \%(N=130)$ & $73.42 \%(N=158)$ & 1.37 & 0.242 \\
Emergence of the first worker & $88.79 \%(N=116)$ & $78.26 \%(N=138)$ & 4.25 & 0.039 \\
\hline
\end{tabular}

Values in italics were significantly different according to Pearson's chi-square test with Yates' correction $(P=0.05)$ 
Table II. Colony development performance depending on the queen's pre-diapause weight. All data show the mean $\pm \mathrm{SE}$

\begin{tabular}{lccccc}
\hline \multicolumn{1}{c}{ Queen/colony performance } & Medium queens & Heavy queens & $t$ & $d . f$. & $P$ \\
\hline $\begin{array}{l}\text { Days between queen placement } \\
\text { in starting box and first egg }\end{array}$ & $7.785 \pm 0.363(N=130)$ & $9.177 \pm 0.373(N=158)$ & -2.756 & 286 & 0.006 \\
$\quad$ deposition & & & & & \\
$\begin{array}{l}\text { Number of produced egg cells } \\
\text { Number of discarded larvae }\end{array}$ & $5.527 \pm 0.164(N=129)$ & $5.272 \pm 0.136(N=158)$ & 1.205 & 285 & 0.229 \\
$\begin{array}{l}\text { Number of pupae in the first } \\
\text { brood }\end{array}$ & $7.965 \pm 0.369(N=113)$ & $2.333 \pm 0.282(N=129)$ & 1.336 & 240 & 0.183 \\
$\begin{array}{c}\text { Estimated mean number of eggs } \\
\text { per cell }\end{array}$ & $1.945 \pm 0.100(N=109)$ & $1.791 \pm 0.087(N=122)$ & 1.244 & 229 & 0.215 \\
$\begin{array}{c}\text { Days between first and second } \\
\text { brood deposition }\end{array}$ & $17.154 \pm 0.376(N=104)$ & $17.974 \pm 0.383(N=116)$ & -1.539 & 218 & 0.125 \\
$\begin{array}{l}\text { Days between first egg } \\
\text { deposition and first emerged }\end{array}$ & $25.505 \pm 0.417(N=103)$ & $27.361 \pm 0.530(N=108)$ & -2.708 & 209 & 0.007 \\
adult & & & & & \\
\hline
\end{tabular}

Values in italics were significantly different according to independent-samples $t$ test $(P=0.05)$

survived to a lower extent $(42.5 \%)$ than medium and heavy queens. However, the surviving light queens showed apparently higher percentages of success than medium and heavy queens in all the following steps of colony development, with $100 \%$ of post-diapause survival and first eggs deposition and $88.2 \%$ in the deposition of the second brood and in the emergence of the first worker.

\subsection{Egg-laying stimulation}

The sex of the pupa used to stimulate the queen did not significantly affect egg laying $\left(\chi_{1}^{2}=0.01\right.$, $P=0.992)$, second brood deposition $\left(\chi_{1}^{2}=2.44\right.$, $P=0.119)$ or emergence of the first individual $\left(\chi_{1}^{2}=0.74, P=0.389\right)$ (Figure 3).

However, the analysis of colony development characteristics showed that queens stimulated with a queen pupa produced a higher number of pupae in the first brood (Table III).

\section{DISCUSSION}

\subsection{Effects of mating status on queen survival}

The higher diapause survival rate of virgin queens compared to mated queens confirms the finding of Greeff and Schmid-Hempel (2008) that mating reduces survival during diapause of $B$. terrestris queens. According to these authors, this is due to the costs of sperm storage in inseminated queen. Although we did not continue the observation of virgin queens after diapause, a recent study showed that virgin queens are able to develop ovaries and to lay unfertilized eggs under laboratory conditions (Amsalem et al. 2015). It is not known if these circumstances happen in nature, but from an evolutionary point of view, there is no clear advantage in the surviving of virgin queens, since they could even compete with mated ones for food resources and nesting sites but they are unable to found a colony. From an applied point of view, our results imply that in order to start a new bumble bee rearing it is important to follow accurately the mating phase to select only queens that have certainly mated, since they cannot be distinguished from virgin queens and queen survival cannot be used as an indicator of mating status. This would lead to employ workforce to rear queens that will not produce colonies.

\subsection{Effect of queen weight on diapause survival and colony initiation}

Unlike the finding of Beekman et al. (1998), who found an effect of queen weight on survival but only to the extent that queens below a certain 

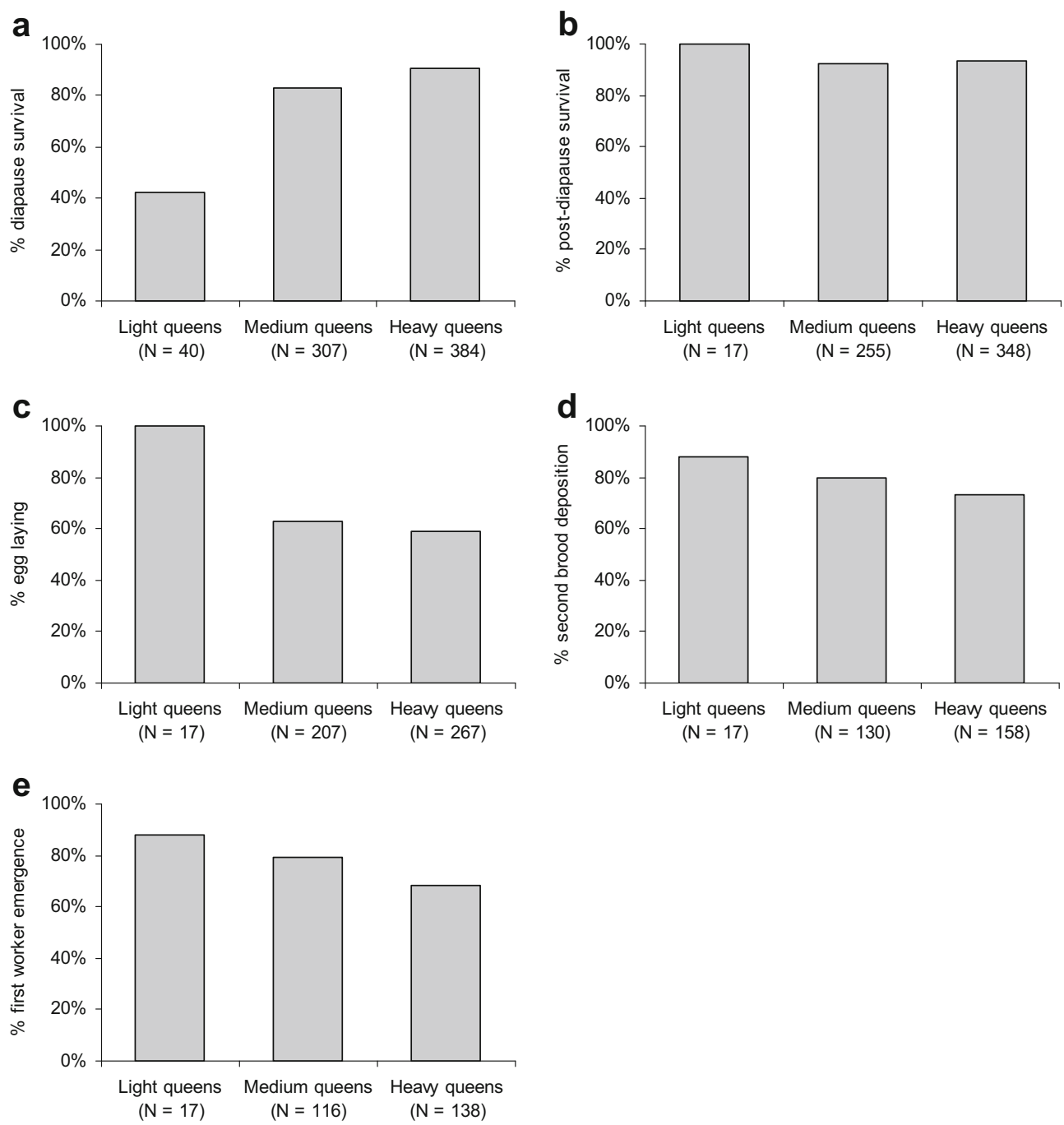

Figure 2. Percentage of queens, depending on the pre-diapause weight, that a survived to diapause period, $\mathbf{b}$ survived to post-diapause period, $\mathbf{c}$ laid the first egg cell, $\mathbf{d}$ laid the second brood and $\mathbf{e}$ had the first worker emerged.

threshold were less likely to survive, our results indicate that queen weight can affect diapause survival, also when it exceeds $0.6 \mathrm{~g}$. In fact, heavy queens, with weight higher than $0.8 \mathrm{~g}$, survived more than lighter queens. Analogously, in a previous study on $B$. terrestris and $B$. lapidarius (Holm 1972), all the queens heavier than $0.842 \mathrm{~g}$ prior to diapause survived to diapause and in another six bumble bee species, Owen (1988) found a positive correlation between the prediapause weight of the queens and their diapause survival. In our study, light queens (i.e. $<0.6$ g) showed lower survival rates than heavier queens, probably due to insufficient fat body reserves (Hodek and Hodková 1988). Nevertheless, when light queens survived the diapause, their ability to generate a colony was perfectly conserved, and they had even higher egg-laying success compared to heavier queens, suggesting that the physiological features determining who is a "high quality queen" are not linked with size. In addition, the severe selection operated by our diapause conditions on smaller queens likely determined an increase in queen quality. The size of workers and 

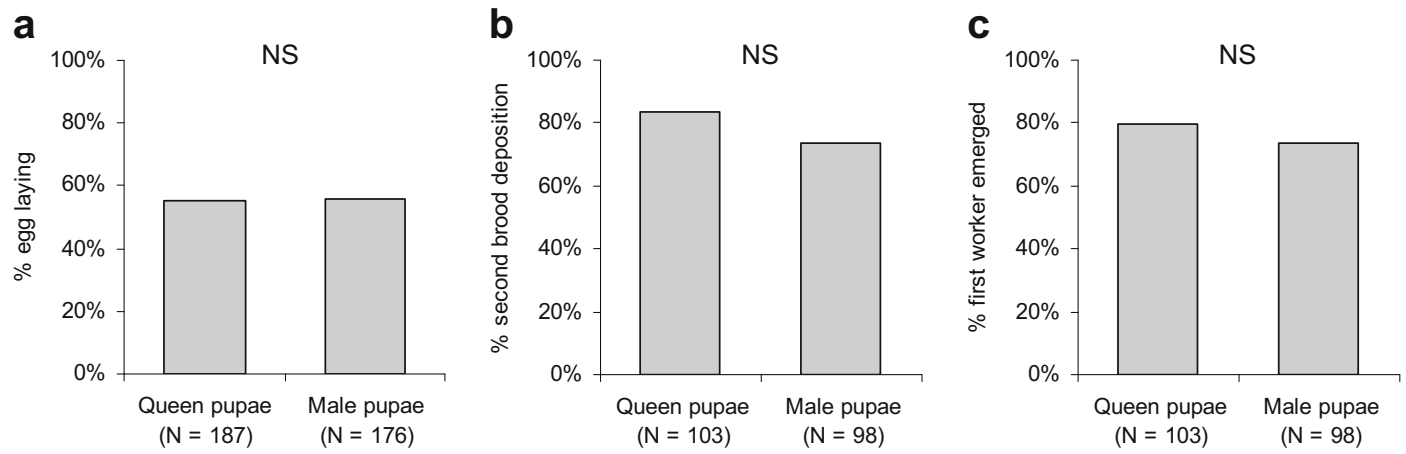

Figure 3. Percentage of queens stimulated with queen and male pupae that a laid the first egg cell, $\mathbf{b}$ laid the second brood and $\mathbf{c}$ had the first worker emerged. NS not significant (Pearson's chi-square test with Yates' correction, $P=0.05)$.

queens of $B$. terrestris is highly variable and in previous studies a female adult was classified as queen when its weight exceeded $0.5 \mathrm{~g}$ (Bortolotti et al. 2001; Pereboom et al. 2003). In this study, we considered as queens all the females able to mate, independently from their weight, and we demonstrated that also small females can succeed as queens in colony foundation.

Despite the higher survival rate of heavy queens, in our study, an increase in the weight of bumble bee queens did not positively affect the size of the first brood, in contrast with previous findings (Gösterit and Gürel 2007). On the contrary, heavy queens required more time to achieve the first egg deposition. Moreover, fewer colonies achieved the development of the first worker and it took longer time compared to medium queens. Light queens apparently had a better performance in colony foundation than heavier queens, although their low number did not allow us to perform a statistical analysis.

Our results regard the early phases of colony development, but it would be interesting to evaluate the effects of queen weight on the complete colony life cycle, e.g. total number of workers, queens and males produced.

\subsection{Egg-laying stimulation}

Egg laying by queen bumble bees reared in controlled conditions benefits from induced stimulation. Gretenkord and Drescher (1997)

Table III. Colony development performance depending on pupae's sex. All data show the mean $\pm \mathrm{SE}$

\begin{tabular}{lccccc}
\hline \multicolumn{1}{c}{ Queen/colony performance } & Queen pupa & Male pupa & $t$ & $d . f$. & $P$ \\
\hline $\begin{array}{l}\text { Days between queen placement in } \\
\text { starting box and first egg }\end{array}$ & $7.689 \pm 0.424(N=103)$ & $8.316 \pm 0.477(N=98)$ & -0.904 & 199 & 0.367 \\
$\quad$ deposition & & & & & \\
Number of produced egg cells & $5.660 \pm 0.181(N=103)$ & $5.245 \pm 0.164(N=98)$ & 1.656 & 199 & 0.099 \\
Number of discarded larvae & $2.730 \pm 0.402(N=89)$ & $2.241 \pm 0.303(N=83)$ & 0.649 & 170 & 0.517 \\
Number of pupae in the first brood & $8.200 \pm 0.412(N=85)$ & $6.481 \pm 0.411(N=81)$ & 2.901 & 164 & 0.004 \\
$\begin{array}{l}\text { Estimated mean number of eggs } \\
\text { per cell }\end{array}$ & $2.022 \pm 0.095(N=86)$ & $1.798 \pm 0.125(N=81)$ & 0.756 & 199 & 0.451 \\
$\begin{array}{c}\text { Days between first and second } \\
\text { brood deposition }\end{array}$ & $16.721 \pm 0.402(N=86)$ & $16.972 \pm 0.437(N=72)$ & -0.463 & 156 & 0.644 \\
$\begin{array}{c}\text { Days between first egg deposition } \\
\text { and first emerged adult }\end{array}$ & $25.256 \pm 0.564(N=82)$ & $24.686 \pm 0.475(N=70)$ & 0.674 & 150 & 0.501 \\
\hline
\end{tabular}

Values in italics were significantly different according to independent-samples $t$ test $(P=0.05)$ 
compared different methods of queen stimulation and found that the most successful consisted in adding some newly emerged bumble bee workers and a clump of female larvae to the queen. However, this method may not be practical for experimental rearing, because of the need to destroy many colonies to obtain workers and larvae; furthermore, after few days, workers start to fight with the queen and need to be removed. The use of a pupa as a stimulus for egg laying seems to be the most practical method, and in several studies, a male pupa was successfully used (Duchateau 2000; Yeninar et al. 2000; Kwon et al. 2003). The choice of male pupae is justified by the fact that they are easy to obtain in large number from old colonies, and the single cocoon can be easily separated from the others (contrarily to worker pupae, whose cocoons are tightly connected to each other). Using queen pupae has the same feasibility than using male pupae and in addition, they remain available to the laying queens for a longer period of time, since pupal development of bumble bees lasts longer for queens than for males (Duchateau and Velthuis 1988). Kwon et al. (2003) found that queens stimulated by a male pupa fixed horizontally produced more workers in the first brood, probably because the queen had a larger area available on which build and incubate the egg cells. We found no difference in the percentage of queens laying on the two types of pupae (55 and $56 \%$ on queen and male pupae, respectively), confirming the efficiency of the male pupa. However, the size of the first brood was larger for the queens stimulated with queen pupae, similarly to the results of Kwon et al. (2003) with the horizontal male pupae. This is likely due to the size of the queen pupa, whose surface is almost twice as that of the male one and consequently, the egg cells can be larger. Additionally, by observing the behaviour of males and queens emerging from the pupae, we hypothesise that the larger brood obtained with the queen pupae is not only linked to their size. When male bumble bees emerge, in fact, they damage the egg cells laid on the top of the pupa, while emerging queens (as the workers) emerge from the side of the pupa safeguarding the egg cells. Moreover, if emerging males are not immediately removed from the box, they start to move around, stepping on and damaging the brood. Emerging queens, on the contrary, help the founder queen in taking care of the brood.

\section{CONCLUSIONS}

Our results indicate that queens obtained from commercial colonies are fit for starting an experimental rearing. We demonstrated that virgin queens survived the diapause to a higher extent than mated ones and therefore, it is important to select only mated queens to have a higher egglaying success. We found that a queen prediapause weight below $0.6 \mathrm{~g}$ strongly affected diapause survival while a pre-diapause weight higher than $0.8 \mathrm{~g}$ was slightly favourable, although heavy queens are slower in developing the colony. Finally, for the first time, we showed that the use of queen pupae stimulated egg laying more effectively than male pupae. Our findings can be particularly useful in small scale and experimental bumble bee rearing, including the rearing of wild queens and the further release of colonies in nature to help bumble bees declining populations and conservation purposes.

\section{ACKNOWLEDGEMENTS}

This work was performed within the Life+ Project PP-ICON (Plant-Pollinator CONservation approach: a demonstrative proposal - LIFE09/NAT/IT000212), funded by the European Union. We thank Bioplanet s.c.a. for supplying the colonies and Laura Zavatta for helping with bumble bee rearing. We also thank the anonymous reviewers for comments on an early version of the manuscript.

\section{AUTHOR'S CONTRIBUTIONS}

GB and LB conceived this research and designed experiments; all authors performed experiments and analysis, wrote the paper and participated in the revisions of it.

Effets du statut des reines -accouplées ou non, de leurs poids avant diapause et du sexe des pupes sur la formation d'une colonie dans le cadre d'un élevage à petite échelle de Bombus terrestris 


\section{Bourdon / début de la colonie / ponte / élevage expéri- mental / diapause}

Effekte des Paarungsstatus von Königinnen, VorDiapause Gewicht und Geschlecht der Puppen für die Kolonieinitierung in kleinräumingen Zuchten von Bombus terrestris

\section{Hummel / Konolieinitierung / Ei-legen / experimentelle Zucht / Diapause}

\section{REFERENCES}

Alford, D. V. (1969) A study of hibernation of bumblebees (Hymenoptera: Bombidae) in southern England. J. Anim. Ecol. 38 (1), 149-170. DOI:10.2307/2743

Amin, M. R., Suh, S. J., Kwon, Y. J. (2007) Effects of photoperiod and hibernation duration on the lifespan of Bombus terrestris. Entomol. Res. 37 (2), 89-94. DOI:10.1111/j.1748-5967.2007.00058.x

Amsalem, E., Grozinger, C. M., Padilla, M., Hefetz, A. (2015) The physiological and genomic bases of bumble bee social behaviour, in: Zayed, A.. and Kent, C. F. (Eds), Genomics, Physiology and Behaviour of Social Insects. Academic Press, Elsevier Ltd, Amsterdam, pp. 37-83.

Beekman, M., Van Stratum, P., Veerman, A. (1998) Diapause survival and post diapause performance in bumble bee queens (Bombus terrestris). Entomol. Exp. Appl. 89 (3), 207-214. DOI:10.1046/j.15707458.1998.00401.x

Beekman, M., Van Stratum, P., Lingerman, R. (2000) Artificial rearing of bumble bees (Bombus terrestris) selects against heavy queens. J. Apic. Res. 39 (1-2), 6165. DOI:10.1080/00218839.2000.11101022

Bortolotti, L., Duchateau, M. J., Sbrenna, G. (2001) Effect of juvenile hormone on caste determination and colony processes in the bumblebee Bombus terrestris. Entomol. Exp. Appl. 101 (2), 143-158. DOI:10.1046 /j.1570-7458.2001.00899.x

Bortolotti, L., Bogo, G., de Manincor, N., Fisogni, A., Galloni, M. (2016) Integrated conservation of bee pollinators of a rare plant in a protected area near Bologna, Italy. Conserv. Evi. 13, 51-56.

Coppée, A., Mathy, T., Cammaerts, M. C., Verheggen, F. J., Terzo, M., et al. (2011) Age-dependent attractivity of males' sexual pheromones in Bombus terrestris (L.) [Hymenoptera, Apidae]. Chemoecology 21 (2), 75-82.

Duchateau, M. J. (1991) Regulation of colony development. Acta Hort. 288 (1), 139-143. DOI: 10.17660 /ActaHortic. 1991.288.17

Duchateau, M. J. (2000) Biological aspects of rearing bumblebees for pollination, in: Sommeijer, M. J. and de Ruijter, A. (Eds), Insect pollination in greenhouse. Royal Library, Den Haag, pp. 25-29.

Duchateau, M. J., Velthuis, H. H. W. (1988) Development and reproductive strategies in Bombus terrestris colonies. Behaviour 107 (3-4), 186-207. DOI:10.1163/156853988X00340

Gösterit, A., Gürel, F. (2007) Effects of weight of queens after diapause on colony development in the bumblebee, Bombus terrestris L. (Hymenoptera: Apidae). Akdeniz Üniversitesi Ziraat Fakültesi Dergisi 20 (1), 67-70.

Gösterit, A., Gürel, F. (2009) Effect of different diapause regimes on survival and colony development in the bumble bee, Bombus terrestris. J. Apic. Res. 48 (4), 279-283. DOI:10.3896/IBRA.1.48.4.08

Greeff, M., Schmid-Hempel, P. (2008) Sperm reduces female longevity and increases melanization of the spermatheca in the bumblebee Bombus terrestris L. Insectes Soc. 55 (3), 313-319. DOI:10.1007/s00040008-1007-4

Gretenkord, C., Drescher, W. (1997) Successful colony foundation and development of experimentally hibernated Bombus terrestris queens depending on different starting methods. Acta Hort. 437 (1), 271-276. DOI: 10.17660/ActaHortic.1997.437.31

Gürel, F., Gösterit, A. (2008) Effects of different starting methods on colony initiation and development of Bombus terrestris L. (Hymenoptera: Apidae) queens. Appl. Entomol. Zool. 43 (1), 113-117. DOI:10.1303 /aez.2008.113

Hodek, I., Hodková, M. (1988) Multiple role of temperature during insect diapause: a review. Entomol. Exp. Appl. 49, 153-165. DOI:10.1111/j.1570-7458.1988. tb02486.x

Holm, S. N. (1972) Weight and life length of hibernating bumble bee queens (Hymenoptera: Bombidae) under controlled conditions. Insect Syst. Evol. 3 (4), 313320. DOI:10.1163/187631272X00184

Kwon, Y. J., Saeed, S., Duchateau, M. J. (2003) Stimulation of colony initiation and colony development in Bombus terrestris by adding a male pupa: the influence of age and orientation. Apidologie 34 (5), 429437. DOI:10.1051/apido:2003039

Kwong, W. K., Engel, P., Koch, H., Moran, N. A. (2014) Genomics and host specialization of honey bee and bumble bee gut symbionts. Proc. Nat. Acad. Sci. 111 (31), 11509-11514. DOI:10.1073/pnas.1405838111

Owen, R. E. (1988) Body size variation and optimal body size of bumble bee queens (Hymenoptera: Apidae). Can. Entomol. 120 (01), 19-27. DOI:10.4039 /Ent12019-1

Pereboom, J. J. M., Velthuis, H. H. W., Duchateau, M. J. (2003) The organisation of larval feeding in bumblebees (Hymenoptera, Apidae) and its significance to caste differentiation. Insectes Soc. 50 (2), 127-133. DOI:10.1007/s00040-003-0639-7

Pouvreau, A., Marilleau, R. (1977) L'élevage des bourdons. Leur utilisation pour la pollinisation des plantes. Cah Liaisons OPIE, 25, 22-27.

Pridal, A., Hofbauer, J. (1998) Activation of laboratoryreared bumblebee queens (Hymenoptera: Apidae, Bombus spp.). Acta Univ. Agric. Silvic. Mendel. Brun. 46, 79-84. 
Ptacek, V. (1991) Trial to rear bumble bees. Acta Hort. 288

(1), 144-148. DOI: 10.17660/ActaHortic.1991.288.18

Ptácek, V. (2001) Some biological aspects of bumble bee (Bombus, Hymenoptera) management. Acta Hortic. $561,279-286$. D O I : 10.17660 /ActaHortic.2001.561.42

Röseler, P. F. (1985) A technique for year-round rearing of Bombus terrestris (Apidae, Bombini) colonies in captivity. Apidologie 16 (2), 165-170.

Shykoff, J. A., Schmid-Hempel, P. (1991) Incidence and effects of four parasites in natural populations of bumble bees in Switzerland. Apidologie 22 (2), 117-125. DOI:10.1051/apido:19910204

Sladen, F. W. L. (1912) The humble bee, its life history and how to domesticate it. Macmillan, London.

StatSoft Italia srl (2005) STATISTICA (sistema software di analisi dei dati), versione 7.1. http://www.statsoft.it

Tasei, J. N., Moinard, C., Moreau, L., Himpens, B., Guyonnaud, S. (1998) Relationship between aging, mating and sperm production in captive Bombus terrestris. J. Apic. Res. 37 (2), 107-113. DOI:10.1080/00218839.1998.11100962

Van Den Eijnde, J., De Ruijter, A., Van Der Steen, J. (1991) Methods for rearing Bombus terrestris continuously and the production of bumble bee colonies for pollination purposes. Acta Hort. 288 (1), 154-158. DOI: 10.17660/ActaHortic.1991.288.20
Van Der Steen, J. J. (2008) Infection and transmission of Nosema bombi in Bombus terrestris colonies and its effect on hibernation, mating and colony founding. Apidologie 39 (2), 273-282. DOI:10.1051 /apido:2008006

Velthuis, H. H. W. (2002) The historical background of the domestication of the bumble bee, Bombus terrestris, and its introduction in agriculture, in: Kevan, P. and Imperatriz Fonseca, V. L. (Eds), Pollinating bees. The conservation link between agriculture and nature. Ministry of Environment, Brasilia, pp. 177-184.

Velthuis, H. H. W., Van Doorn, A. (2006) A century of advances in bumblebee domestication and the economic and environmental aspects of its commercialization for pollination. Apidologie 37 (4), 421-451. DOI:10.1051/apido:2006019

Yeninar, H., Duchateau, M. J., Kaftanoglu, O., Velthuis, H. H. W. (2000) Colony developmental patterns in different local populations of the Turkish bumble bee, Bombus terrestris dalmatinus. J. Apic. Res. 39 (34), 107-116. DOI:10.1080/00218839.2000.11101030

Yoon, H. J., Kim, S. E., Lee, K. Y., Lee, S. B., Park, I. G. (2008) Copulation environment favorable for colony development of the European Bumblebee, Bombus terrestris . Int. J. Indust. Entomol. 16 (1), 7-13. 